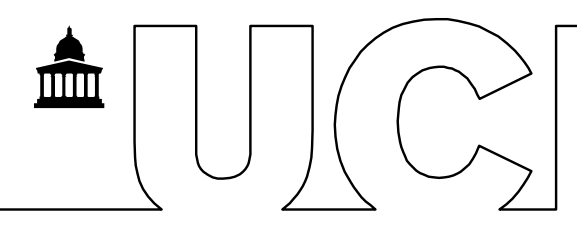

Marí-Dell'Olmo, M; Gotsens, M; Palència, L; Burström, B; Corman, D; Costa, G; Deboosere, P; (2015) Socioeconomic inequalities in cause-specific mortality in 15 European cities. Journal of Epidemiology \& Community Health, 69 (5) pp. 432-441. 10.1136/jech-2014-204312.

Downloaded from UCL Discovery: http://discovery.ucl.ac.uk/1460203

\title{
ARTICLE
}

\section{Socioeconomic inequalities in cause-specific mortality in fifteen European cities}

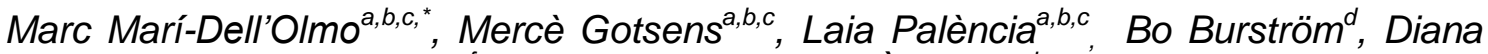
Corman $^{e}$, Giuseppe Costa ${ }^{f}$ Patrick Deboosere ${ }^{g}$, Èlia Díez ${ }^{b, a, c}$, Felicitas DomínguezBerjón ${ }^{h}$, Dagmar Dzúrovái, Ana Gandarillas', Rasmus Hoffmann', Katalin Kovacs ${ }^{k}$, Pekka Martikainen', Demaria Moreno ${ }^{m}$, Hynek Pikhart', Maica Rodríguez-Sanz ${ }^{b, a, c}$, Marc Saez ${ }^{o, a}$, Paula Santana ${ }^{p}$, Cornelia Schwierz ${ }^{q}$, Lasse Tarkiainen', Carme Borrelp,a,r,c

${ }^{a}$ CIBER Epidemiología y Salud Pública (CIBERESP). Madrid, Spain

${ }^{b}$ Agència de Salut Pública de Barcelona. Barcelona, Spain

${ }^{c}$ Institut d'Investigació Biomèdica (IIB Sant Pau). Barcelona, Spain

${ }^{d}$ Karolinska Institutet, Department of Public Health Sciences, Division of Social Medicine, Stockholm, Sweden

${ }^{e}$ Karolinska Institutet, Department of Public Health Sciences, Division of Social Medicine, Stockholm, Sweden

${ }^{f}$ Department of Clinical and Biological Science, University of Turin, Turin, Italy

${ }^{g}$ Department of Social research, Vrije Universiteit Brussel, Brussels, Belgium

${ }^{n}$ Subdirección de Promoción de la Salud y Prevención. Consejería de Sanidad. Comunidad de Madrid, Spain

'Department of Social Geography and Regional Development, Faculty of Science, Charles University in Prague, Prague, Czech Republic

${ }^{j}$ Department of Public Health, Erasmus Medical Center, Rotterdam, The Netherlands

${ }^{k}$ Demographic Research Institute, Budapest, Hungary

' Department of Social Research, University of Helsinki, Helsinki, Finland

${ }^{m}$ Department of Epidemiology and Environmental Health, Regional Agency for Environment Protection of Piedmont, Italy

${ }^{n}$ Department of Epidemiology and Public Health, University College London, London, UK

${ }^{\circ}$ Research Group on Statistics, Econometrics and Health (GRECS), University of Girona, Girona, Spain

${ }^{p}$ Centro de Estudos de Geografia e de Ordenamento do Territorio (CEGOT),

Departamento de Geografia, Colégio de S. Jerónimo, Universidade de Coimbra,

Coimbra, Portugal

a Statistik Stadt Zürich, Zürich, Switzerland

r Universitat Pompeu Fabra, Barcelona, Spain

* Address for correspondence: Marc Marí-Dell'Olmo, Agència de Salut Pública de Barcelona, Plaça Lesseps 1, 08023 Barcelona; Telephone: 34-93-2384545; E-mail: mmari@aspb.cat 


\begin{abstract}
Background

Socioeconomic inequalities are increasingly recognised as an important public-health issue, although their role in the leading causes of mortality in urban areas in Europe has not been fully evaluated. In this study, we used data from the INEQ-CITIES study to analyse inequalities in cause-specific mortality in fifteen European cities at the beginning of the $21^{\text {st }}$ century.
\end{abstract}

\title{
Methods
}

A cross-sectional ecological study was carried out to analyse 9 of the leading specific causes of death in small areas from 15 European cities. Using a hierarchical Bayesian spatial models, we estimated smoothed Standardized Mortality Ratios, relative risks and $95 \%$ credible intervals for cause-specific mortality in relation to a socioeconomic deprivation index, separately for men and women.

Results

We detected spatial socioeconomic inequalities for most causes of mortality studied, although these inequalities differed markedly between cities, being more pronounced in Northern and Central-Eastern Europe. In the majority of cities, most of these causes of death were positively associated with deprivation among men, with the exception of prostatic cancer. Among women, diabetes, ischemic heart disease, chronic liver diseases, and respiratory diseases were also positively associated with deprivation in most cities. Lung cancer mortality was positively associated with deprivation in Northern European cities and in Kosice, but this association was non-existent or even negative in Southern European cities. Finally, breast cancer risk was inversely associated with deprivation in three Southern European cities.

\section{Conclusions}

The results confirm the existence of socioeconomic inequalities in many of the main causes of mortality, and reveal variations in their magnitude between different European cities.

\section{Funding}

Executive Agency for Health and Consumers (European Commission), project no. 2008-12-13.

\section{Introduction}

Over the past few decades, the world's population has undergone rapid urbanisation, which first started, and continues to occur, in today's most developed regions. The United Nations' Department of Economic and Social Affairs indicates that $51.3 \%$ of the European population lived in urban areas in 1940, increasing to $72.9 \%$ in 2011 . This percentage is projected to rise to $82.2 \%$ by 2050 , representing some 591 million people.[1]

Given the growth in the urban population, public health challenges are increasingly concentrated in urban areas and policies must be adapted to this context. An important challenge for health policymaking posed by urbanisation is to reduce health inequalities within and between cities. Studies of health inequalities in the urban context allow us to identify the factors and processes (determinants) that drive inequalities, how these determinants contribute to inequalities, and how do they differ between cities or between urban and rural areas.[2] These elements are critical for tailoring policies to reduce health inequalities.

One of the most commonly used indicators to study socioeconomic inequalities in health is mortality. A number of recent studies have reported socioeconomic 
inequalities in mortality at individual level in various European countries.[3-9] Moreover, it has been shown that the magnitude of these inequalities differs substantially between countries, and a spatial pattern in some of the specific causes of mortality has been proposed. In general, inequalities are most subtle in Southern European countries and more marked in some Eastern and Northern European countries. For example, important socioeconomic inequalities in lung cancer mortality have been detected in Europe, with much higher rates among the most poorly educated men and women from some Eastern and Northern European countries, respectively. [5,9] Another clear example is that of mortality from ischemic heart disease, where various studies (not including Eastern European countries) have found greater socioeconomic differences in Northern compared to Southern European countries. $[4,6,7,10]$

However, these studies analysed the entire population of the target country, precluding an evaluation of intra- and inter-urban inequalities, such that their results may not be informative for national or municipal policymaking.[11] Moreover, while contextual (area level) factors are increasingly considered as important health determinants, previous studies have generally focused on individual factors. Thus, studying socioeconomic inequalities in health by analysing small areas in an urban context is a useful approach.

While previous studies have analysed area-level socioeconomic inequalities in mortality in urban areas in one country,[12,13] the "Socioeconomic inequalities in mortality: evidence and policies in cities of Europe" (INEQ-CITIES) project provides an excellent opportunity to study and compare these inequalities in urban areas across Europe.[14] In fact, recently an article has been published studying socioeconomic inequalities in total mortality,[15] but more in-depth study by the main causes of mortality is needed. Therefore, the objective of this study was to analyze spatial socioeconomic inequalities in cause-specific mortality in fifteen large European cities, stratified by sex, at the beginning of the $21^{\text {st }}$ century.

\section{Methods}

Study design and unit of analysis

We performed a cross-sectional ecological study as part of the INEQ-CITIES project.[14] The units of analysis were small areas (census tracts, parish areas, neigbourhoods or districts; Table 1) in 15 cities and metropolitan areas of several European countries: Helsinki (Finland) and Stockholm (Sweden) in Northern Europe; Budapest (Hungary), Kosice and Bratislava (Slovak Republic), and Prague (Czech Republic) in the Central-Eastern Europe; London (UK), Amsterdam and Rotterdam (the Netherlands), Zurich (Switzerland) and Brussels (Belgium) in Western Europe; Turin (Italy), Madrid and Barcelona (Spain), and Lisbon Metropolitan Area (hereafter called Lisbon) (Portugal) in Southern Europe. The selection of these cities was based on the availability of data through INEQ-CITIES partners. It should be noted that although Paris has been part of the INEQ-CITIES project, it could not be included in this analysis because cause-specific mortality data were not available.

Study population, mortality and information sources

The study population consisted of individuals of all ages resident in the 15 cities. The majority of cities had mortality data for the years 2000-2008 (Table 2) and socioeconomic indicators for 2001. Sex-stratified mortality data and small area were obtained from national mortality registers, and population data stratified by age (fiveyear groups), sex and small area were obtained from census data or municipal registers in each city. Socio-economic indicators were also obtained from census data in most cities. Additional information is available in the online atlas.[16] 
We analysed nine specific individual diseases (see Table 2 for ICD codes), selected as the principal specific causes of death within each of a series of broad disease groups. Thus, diseases of the circulatory system were represented by (i) ischemic heart disease and (ii) cerebrovascular disease; neoplasms were represented by (iii) lung, (iv) prostatic (in men), and (v) breast (in women) cancer; disease of the respiratory system were represented by (vi) respiratory diseases and (vii) influenza and pneumonia; diseases of the digestive system were represented by (viii) chronic liver disease; and finally endocrine, nutritional and metabolic diseases were represented by (ix) diabetes. Note that these are not the nine principal causes of death, but rather the principle causes of death in Europe within each of these disease groups.

\section{Socioeconomic deprivation}

We included as an explanatory variable an index of socioeconomic deprivation calculated for each city using a method based on $\mathrm{P}_{2}$-Distance $\left(\mathrm{DP}_{2}\right),[17]$, which generates an index that is comparable between cities, and which comprises the following indicators: unemployment rate (percentage of unemployed in the active population); percentage of manual workers in the working population; percentage of individuals aged 25-64 years with primary or lower level of education; percentage of individuals aged 25-34 years with university education; and the percentage of foreigners from low income countries. Higher values of the index indicate higher levels of deprivation. Note that educational level was assigned according to the International Standard Classification of Education (ISCED): individuals with an ISCED value of 0,1 or 2 in Helsinki and Budapest, or of 0 or 1 in all other cities were designated as having primary education or lower. Although the INEQ-CITIES project collected information on other socioeconomic indicators, the socioeconomic indicators that were used to create this index were the most comparable indicators across the cities. More information about the process of constructing this index can be found at Hoffmann R. et al. [18]

Data analysis

We calculated Indirectly Standardized Mortality Rates (ISMR) for each city, taking mortality rates of the European Union (25 countries) for the year 2004 as the reference, and stratified by age (in 5 year groups) and cause of death (according to the World Health Organization).[19]

The mortality indicator used for this analysis was the Standardized Mortality Ratio (SMR). The SMR is dependent on population size since its variance is inversely proportional to the expected values, such that areas with low population tend to have estimates with high variance. In order to smooth the SMR, we used the hierarchical Bayesian model proposed by Besag, York and Mollié (BYM).[20] This model takes two types of random effects into account, spatial and heterogeneous, the former accounting for the spatial structure of the data, and the latter dealing with non-structural (nonspatial) variability. The smoothed SMR (sSMR) was estimated for each cause of death, sex and city using the following model:

$$
\begin{aligned}
& O_{i} \sim \operatorname{Poisson}\left(E_{i} \theta_{i}\right) \\
& \log \left(\theta_{i}\right)=\alpha+S_{i}+H_{i}
\end{aligned}
$$

where for each area $i, O_{i}$ is the observed number of cases, $E_{i}$ the expected number of cases, $\theta_{i}$ is the relative risk with respect to the European population, $S_{i}$ is the spatial effect, and $H_{i}$ is the heterogeneous effect. The expected number of cases in each small area was calculated by indirect standardization using the same reference rates as for the ISMR calculation above, but with additional stratification by sex. 
The geographical distribution of the SMR calculated using model 1 and the deprivation index were represented as septile maps (see Figure 1), generated using R.[21]

In order to analyse the relationship between mortality and socioeconomic deprivation, we fitted an ecological regression model (model 2) including the deprivation index $\left(X_{i}\right)$ as an explanatory variable:

$$
\begin{array}{ll}
O_{i} \sim \operatorname{Poisson}\left(E_{i} \theta_{i}\right) & \text { (model 2), } \\
\log \left(\theta_{i}\right)=\alpha+\beta X_{i}+S_{i}+H_{i} &
\end{array}
$$

where $e^{\beta}$ denotes the relative risk (RR) associated with the deprivation index.

In both of these models (model 1 and model 2), an intrinsic conditional autoregressive prior distribution (ICAR)[20] was assigned to the spatial effect, which assumes that the expected value of each area coincides with the mean of the spatial effect of the adjacent areas and has variance of $\sigma_{s}^{2}$, while the heterogeneous effect was represented using independent normal distributions with mean of 0 and variance of $\sigma_{h}^{2}$. A half-normal distribution with mean of 0 and precision of 0.0001 was assigned to the standard deviations $\sigma_{s}$ and $\sigma_{h}$.[22] A normal vague prior distribution was assigned to the parameters $\alpha$ and $\beta$.

Relative risk (RR) estimates were based on their posterior means and 95\% credible intervals $(95 \% \mathrm{Cl})$. A RR would be considered significantly higher or lower than 1 if its $95 \% \mathrm{Cl}$ does not include the 1. Posterior distributions were obtained using the "Integrated nested Laplace approximation" (INLA) method, implemented in the R INLA library (version 3.0.1).[23,24] This method provides reliable estimates of the posterior distributions, while avoiding the problems and computing time required for Monte Carlo methods.

Analyses were performed for each cause of death and city, and stratified by sex in order to control for possible interactions between socio-economic deprivation and sex.

\section{Results}

The number of small areas, total population and the distribution of the population by small area in each city and for each sex are shown in Table 1. The number of small areas per city varies from 17 in Bratislava to 2666 in Turin, and the median population size per small area ranges from 274 in Turin to 76,970 in Budapest. Table 1 also shows descriptive statistics of the socioeconomic deprivation index, which varied from a median of 3.2 in Stockholm to 7.8 in Madrid. Table 2 shows the number of deaths and ISMR in each city, stratified by sex and cause of death. In the majority of cities, the most common cause of death in both sexes was ischemic heart disease, followed by cerebrovascular disease and, in men, lung cancer.

Maps of the geographical distributions of mortality and deprivation in Helsinki, Prague, London and Madrid are shown in Figure 1; similar maps for the other causes of death, cities and sexes are available via the online INEQ-CITIES atlas.[16] Moreover, this atlas also contains complementary maps showing the probability of excess risk (sSMR $>100$ ), which should also be taken into account when evaluating the statistical evidence provided by estimates of SSMR in each small area. For example, this figure suggests that the spatial pattern of the deprivation index in Helsinki is similar to that of mortality due to diabetes, and likewise for ischemic heart disease in London. Interestingly, the spatial pattern of the deprivation index in Madrid is similar to that of 
mortality due to lung cancer among men, but this relationship is reversed among women. Finally, the pattern of mortality due to chronic liver diseases does not appear to be related to that of the deprivation index in Prague.

The results of the analysis of association between the deprivation index and the specific causes of death in men are shown in Figure 2. In general, we observed a positive association between the deprivation index and cause-specific mortality in most cities, i.e. most RRs are significantly higher than 1 . The highest RRs were observed for chronic liver disease and respiratory disease. Conversely, prostatic cancer was generally not associated with deprivation, with the exception of the inverse relationship observed in Madrid ( $\mathrm{RR}=0.984 ; 95 \% \mathrm{Cl}$ : 0.969-0.998). In general, mortality was most significantly associated with deprivation in Northern and Central-Eastern European cities.

The results of the analysis of association between the deprivation index and specific causes of death in women are shown in Figure 3. Diabetes, ischemic heart disease, chronic liver diseases, and respiratory diseases were significantly associated with deprivation in most cities, with the highest RRs in chronic liver disease and diabetes. Moreover, as in men, the strongest significant positive associations with deprivation were observed in Northern and Central-Eastern European cities. While lung cancer mortality was significantly inversely associated with deprivation in two southern cities, Lisbon and Madrid, it was significantly directly associated with deprivation in most other cities, with the highest RRs in Helsinki, Stockholm and Kosice. Breast cancer was inversely associated with deprivation in Madrid, Barcelona and Lisbon, no relationship was observed in the remaining cities, except in Budapest where we found a positive association. Influenza and pneumonia were inversely associated with deprivation in Madrid, and directly associated with deprivation in London, Rotterdam and Kosice.

\section{Discussion}

In this study, we report clear evidence of area level socioeconomic inequalities in most of the leading specific causes of mortality, although these inequalities differ between European cities, and are more pronounced in Northern and Central-Eastern Europe. Among men, the majority of specific causes of death were directly associated with deprivation in most cities, with the exception of prostatic cancer. Among women, diabetes, ischemic heart disease, chronic liver diseases, and respiratory diseases were directly associated with deprivation in most cities. Lung cancer mortality was directly associated with deprivation in northern cities and in Kosice, but this association was non-existent or even inverse in southern cities. Finally, breast cancer mortality was inversely associated with deprivation in three southern cities.

Our findings on socioeconomic inequalities in mortality at area level in an urban context go in the same direction as those of other studies on socioeconomic inequalities in mortality that have analysed individual level data from various European countries.[5$8,10,25,26]$ In these studies, socioeconomic inequalities in mortality were proposed to be principally attributable to inequalities in health-related behaviours such as smoking, alcohol consumption, dietary habits, and sedentarism. Moreover, it has been suggested that the spatial patterns of inequalities observed across Europe are partly due to the timing of the behavioural epidemic in each context, which may also vary between sexes and social classes.[27] For example, the smoking epidemic is known to be at a more advanced 'phase' in northern compared to southern Europe, $[5,10]$ among men compared to women, and among advantaged compared to disadvantaged social classes. Thus, while we have observed clear socioeconomic inequalities in lung cancer mortality among women in northern cities, these inequalities were non-existent or even negative in southern cities. Notably, detrimental health behaviours are not only individual factors but must be considered in the context of the material constraints of 
everyday life, and the level of access a person may have to fundamental health determinants. $[13,28]$

Breast cancer mortality was inversely associated with deprivation in three Southern European cities while in other cites no association was found, with the exception of Budapest, where we have found a positive association. This heterogeneity in the results between cities is not easy to explain, and there are probably several reasons partially contributing to this difference in results. First of all, delayed first birth is associated with increased breast cancer risk, which together with the fact that most educated women tend to delay birth due to education and occupational commitments, could explain the inverse association in Southern cities.[9] Smaller differences in delaying first birth by educational level could partially explain the non-existence of an association in several other cities.[29,30]. Moreover, there is an increasing evidence showing that some health related behaviours, such as alcohol intake, increase the risk of breast cancer and this is more frequent among disadvantaged social classes.[31,32] The type of breast cancer screening programs could also have a role in the socioeconomic inequalities in breast cancer mortality.[33] Finally, socioeconomic inequalities in breast cancer mortality could be explained by different treatments offered to patients in different socioeconomic groups.[34]

Area of residence can also play an important role in socioeconomic inequalities in health. Factors such as government institutions (local, regional and national), physical environment (climate, geography, urban planning and housing, food security and access to healthy food, etc.), socioeconomic environment (employment and working conditions, public policies, etc.), settings (where people actively use and shape the environment) and segregation (separation into groups along axes of inequality, such as social class or race), and their complex inter-relations, can influence health inequalities.[2] Moreover, a key element is the fact that people with lower socioeconomic status are more likely to live in areas where these factors tend to be more detrimental to health.[27,35] These factors explain a part of socioeconomic inequality in mortality beyond that explained by individual factors, such as social class or level of education. Additionally, the effects of these factors on inequalities may differ between cities, which could explain the variability (and the spatial patterns) in the inequalities observed between cities.

In general, the association between socioeconomic deprivation and cause-specific mortality appears to be highest in northern cities (Helsinki and Stockholm), which also have the lowest levels of deprivation and the most developed welfare systems. This paradox has been reported previously[36] and we now confirm it in an urban context. Understanding the basis of this paradox is not trivial and several theories have recently been proposed. Mackenbach[37] suggests that the most plausible reasons are (1) that inequalities in access to material and immaterial resources persist; (2) that, due to upward social mobility in successive generations, the composition of lower socioeconomic strata has become more homogeneous with regard to individual characteristics associated with ill-health; and (3) that a change in epidemiological regime, in which consumption behaviour has become the most important determinant of ill-health, has increased the marginal benefits of immaterial resources to which with higher social position gives access.

\section{Limitations and strengths}

The main limitation of this study is the comparability of cities in which the numbers and sizes of the small areas differ markedly.[38] In particular, our analysis may be susceptible to the so-called Modifiable Areal Unit Problem (MAUP), especially in the cities with large populations in a small number of areas.[39] The MAUP explain why 
some associations are difficult to detect and those detected are more likely to be underestimated or spurious.[40-42] This problem could be particularly important in Central-Eastern cities because geographical units are larger than in cities from other regions and, for this reason, it is difficult to show any substantial difference in patterns between cities in this and other regions. However, areas were small in most cities, allowing a high level of spatial disaggregation in the results. Among other advantages, the small size of these areas allows us to represent our results in high resolution maps capable of reflecting spatial patterns that would remain hidden if larger areas were used. Another factor that could affect the comparability is that some cities include metropolitan areas (e.g. Lisbon, which includes inner city parishes and suburban areas) while most other cities do not. On the other hand, large advantage of the study is that substantial effort has been made to collect socioeconomic indicators as similar between cities as possible in order to ensure maximum comparability of the final deprivation index. However, the variability in the deprivation index among city areas in Central-Eastern Europe seem to be smaller than in other cities, which could indicate a better discriminatory power of the index between areas in the cities of North, South and West of Europe. In this sense, perhaps using exactly the same definition of the socioeconomic indicators across cities might also be a limitation. For example, the discriminatory power of the indicators based on the education level could depend to a large extend on the age range of compulsory education and how the access of education has changed through the years in each city. Moreover, other socioeconomic factors (not included in the index) may be more relevant in terms of discriminatoy power in the Central-Eastern cities. Another limitation could be that the contextual effect of the deprivation on mortality is not controlled by relevant individual-level confounders (as with a multilevel analysis). Therefore, apart from age and sex (the results are age-standardized and stratified by sex), the contextual effect could be biased by the existence of other individual-level effects. Finally, the study's main strength is that it is the first to include data on specific-cause mortality from fifteen European cities across Europe, representing heterogeneous socioeconomic and epidemiological contexts and providing an overall view of the behaviour of these causes in urban areas. Finally, the completion of the INEQ-CITIES project is an important achievement in itself, given the difficulty associated with heterogeneity in data collection systems and setting-specific realities.[43]

This study supports the existence of area-level socioeconomic inequalities in most of the leading causes of mortality in urban contexts. Moreover, these inequalities often vary between cities and show a broad spatial trend across Europe. These results highlight the need to implement effective policies to reduce inequalities. Most importantly, these policies must be suited to each city's context, and consider not only health determinants but also how their influence on health inequalities can vary between urban areas. Moreover, our results should be transferred to stakeholders capable of promoting social improvements.[44] Finally, in this study, homogeneous data collection at small area level for 15 European cities has been a challenge. To facilitate the development of small area studies in Europe and increase comparability between studies, it would be useful to define a common European small area to be time invariant and homogeneous in the number of inhabitants, and various official records should attempt to provide information at this level of disaggregation. This may be especially problematic given the differences in personal data confidentiality rules between countries.

\section{What is already known on this subject:}

- In Europe, socioeconomic inequalities in cause-specific mortality at individual level have been studied, and the majority of studies have focused on comparisons between countries. 
- Previous studies have analyses area-level socioeconomic inequalities in mortality in urban areas in one country.

\section{What this study adds:}

- This is the first study to include data on specific cause mortality form fifteen European cities across Europe, representing heterogeneous socioeconomic and epidemiological contexts and providing an overall view of the behaviour of these causes in urban areas.

- There are spatial socioeconomic inequalities for most causes of mortality studied, although these inequalities differed markedly between cities, being more pronounced in Northern and Central-Eastern Europe.

- This type of analysis allows detection of geographical patterns and of areas with higher mortality risk and worse socioeconomic indicators which are susceptible to specific interventions.

Figure 1: Distribution of Smoothed Standardized Mortality Ratios (sSMR) for men and women of diabetes (Helsinki), chronic liver disease (Prague), ischemic heart disease (London) and lung cancer (Madrid), and of the index of deprivation in septiles. Dark grey areas are those with high sSMR and high socioeconomic deprivation.

Figure 2: Association between mortality and socioeconomic deprivation. Relative Risk $(\mathrm{RR})$ and $95 \%$ credible interval $(95 \% \mathrm{Cl})$. Men.

Figure 3: Association between mortality and socioeconomic deprivation. Relative Risk (RR) and 95\% credible interval $(95 \% \mathrm{Cl})$. Women.

Figure 1:
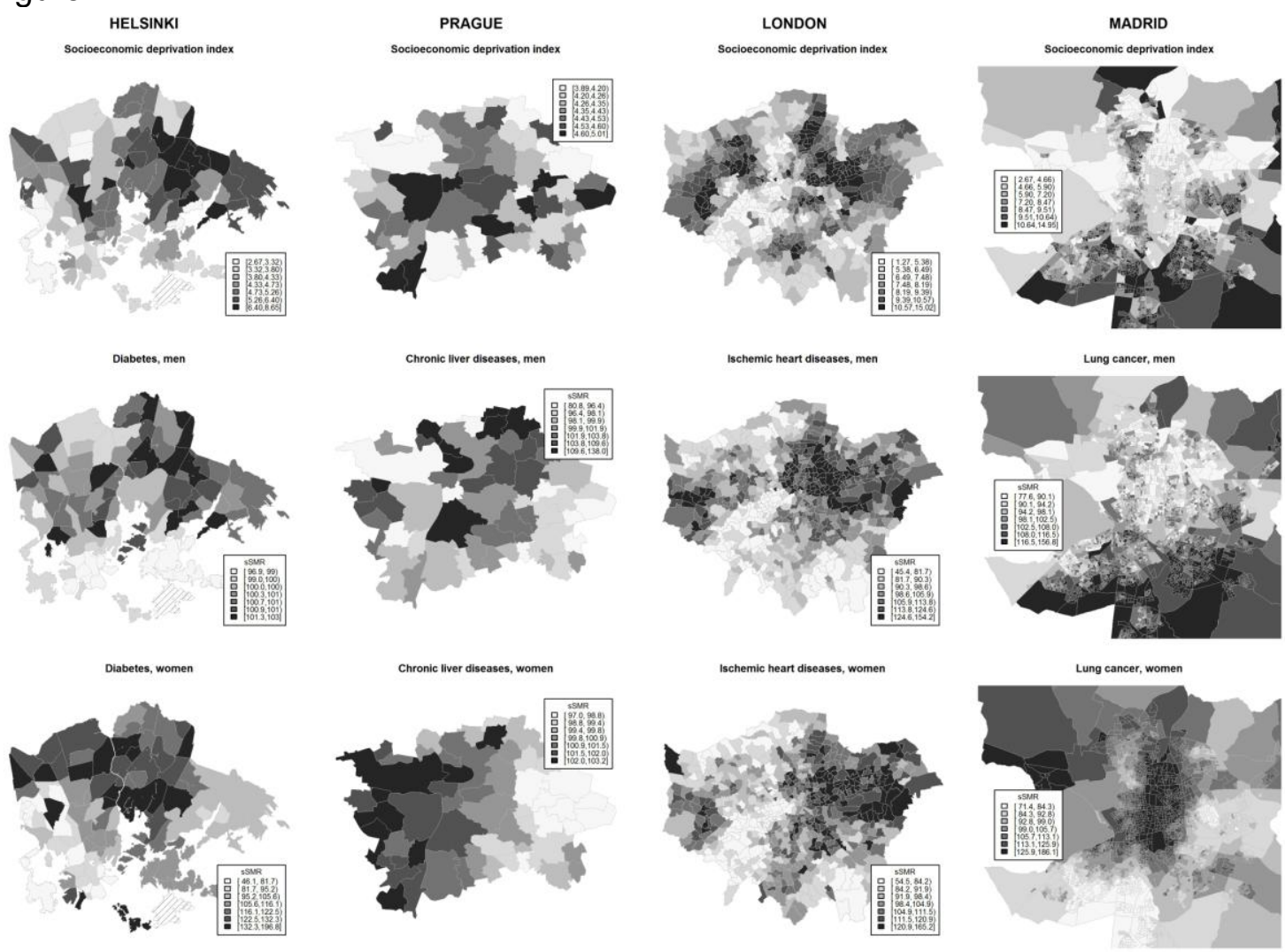
Figure 2:
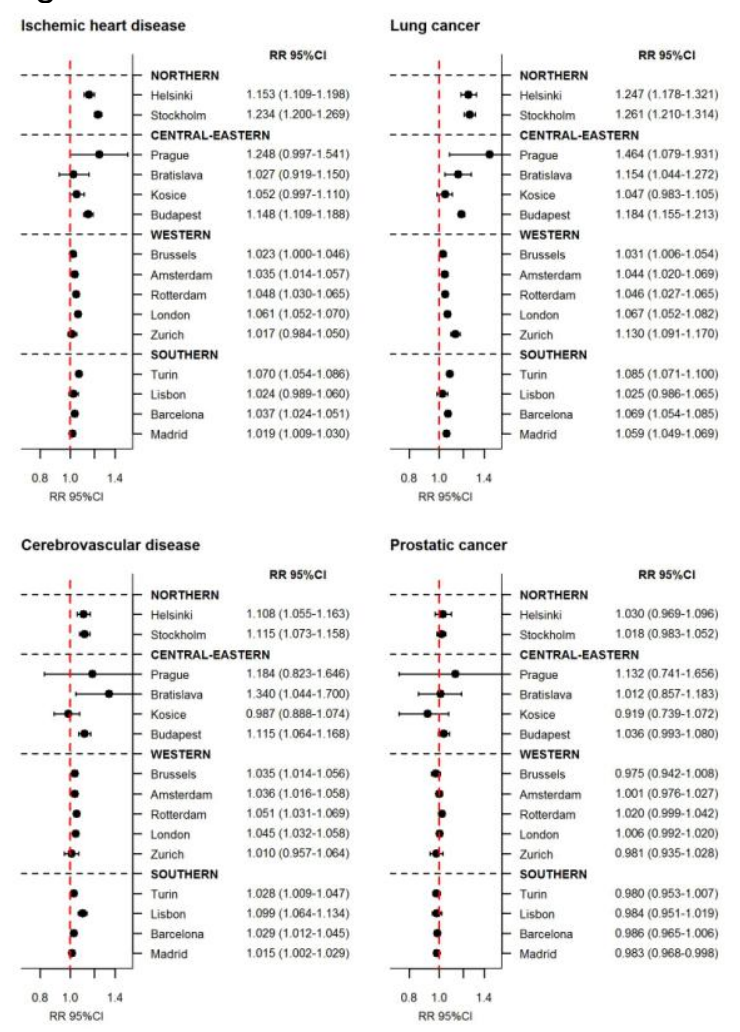

Figure 3:
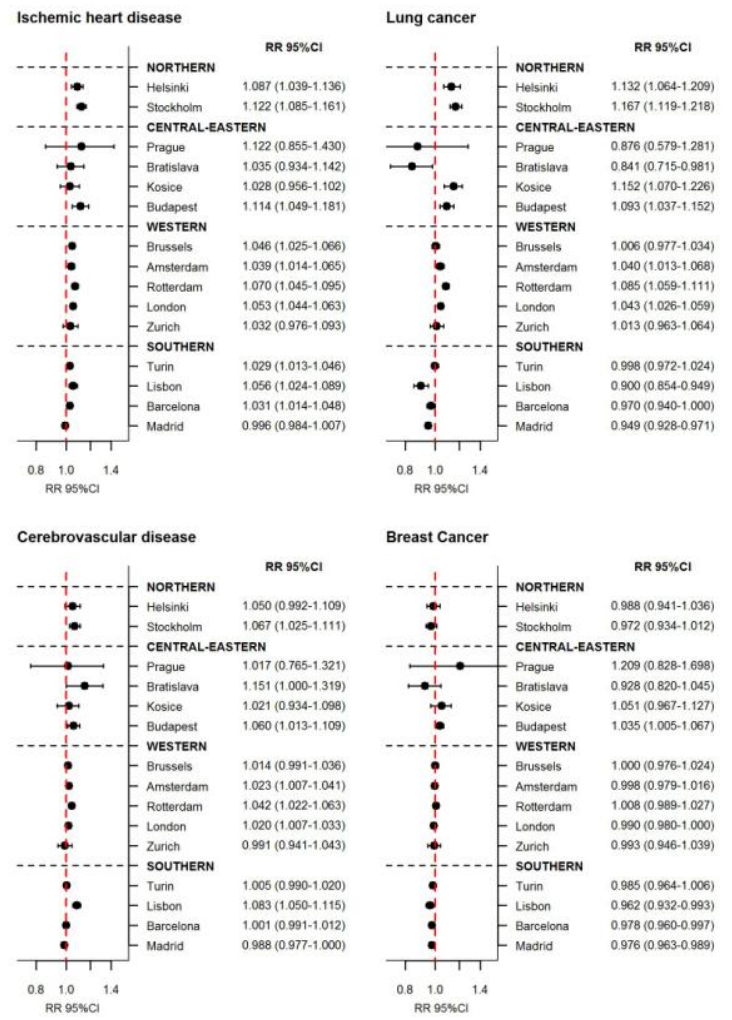

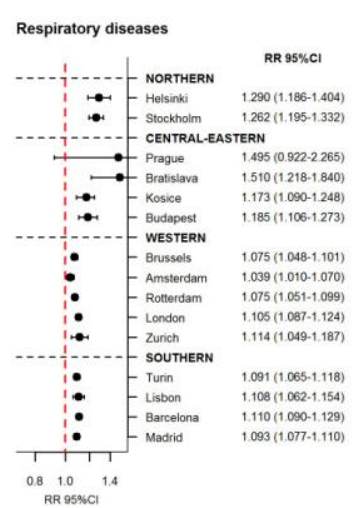

Chronic liver diseases

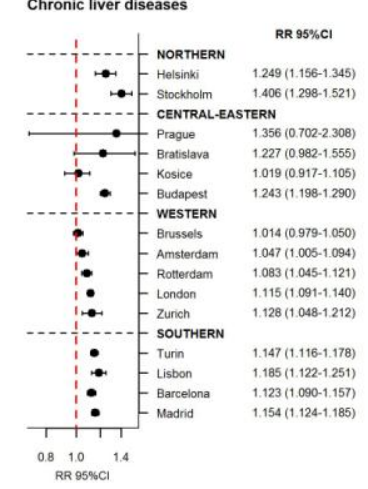

Influenza and Pneumoni
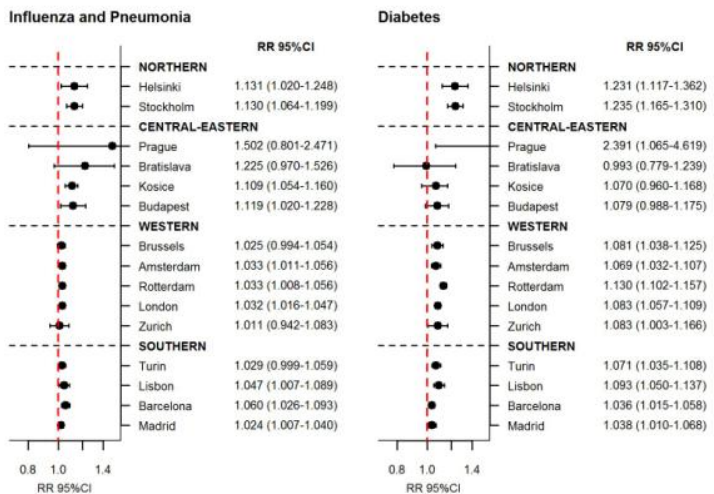

Respiratory diseases
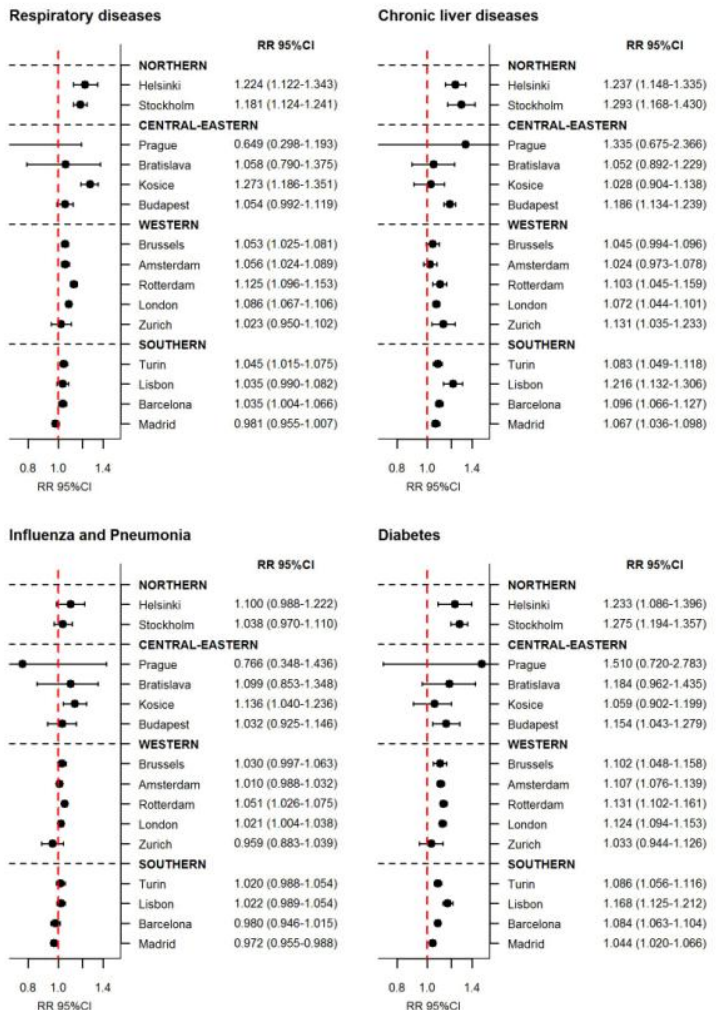

Diabetes

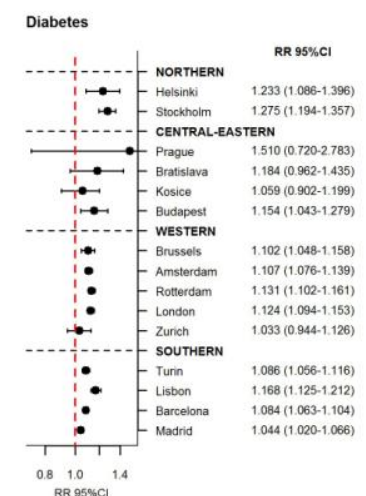


Table 1: Number of small areas, population year, total population and its distribution across areas, and the socioeconomic deprivation index in each city.

\begin{tabular}{|c|c|c|c|c|c|c|c|c|c|c|c|}
\hline \multirow[b]{2}{*}{ European Region } & \multirow[b]{2}{*}{ City } & \multirow[b]{2}{*}{ N. of areas } & \multirow[b]{2}{*}{ Type of area } & \multicolumn{5}{|c|}{ Total Population* } & \multicolumn{3}{|c|}{$\begin{array}{l}\text { Socioeconomic } \\
\text { Deprivation } \\
\text { Index }\end{array}$} \\
\hline & & & & Year & Total & $\mathbf{P}_{25}$ & $\mathbf{P}_{50}$ & $\mathbf{P}_{75}$ & $\mathbf{P}_{25}$ & $\mathbf{P}_{50}$ & $\mathbf{P}_{75}$ \\
\hline \multirow[t]{2}{*}{ Northern } & Helsinki & 94 & Census tract & $\overline{2004}$ & 542,701 & 2962 & 4962 & 7965 & 3.58 & 4.55 & 5.31 \\
\hline & Stockholm & 1172 & Census tract & 2004 & $1,864,359$ & 487 & 1202 & 2193 & 2.59 & 3.20 & 4.09 \\
\hline \multirow[t]{4}{*}{ Central-Eastern } & Prague & 57 & Neighbourhood & 2004 & $1,170,571$ & 1768 & 3197 & 27,210 & 4.25 & 4.37 & 4.54 \\
\hline & Bratislava & 17 & Neighbourhood & 2004 & 425,156 & 2354 & 18,720 & 34,590 & 3.94 & 4.52 & 4.85 \\
\hline & Kosice & 22 & Neighbourhood & 2004 & 235,241 & 1238 & 3373 & 22,700 & 5.71 & 6.51 & 7.68 \\
\hline & Budapest & 23 & District & 2004 & $1,705,309$ & 58,390 & 76,970 & 91,100 & 5.48 & 6.41 & 6.97 \\
\hline \multirow[t]{5}{*}{ Western } & Brussels & 118 & Census tract & 2001 & 970,037 & 5767 & 7779 & 10,620 & 5.51 & 7.13 & 9.29 \\
\hline & Amsterdam & 94 & Census tract & 2001 & 738,325 & 3518 & 7582 & 11,510 & 4.26 & 6.45 & 8.79 \\
\hline & Rotterdam & 88 & Census tract & 2001 & 600,022 & 867 & 6595 & 10,540 & 4.90 & 6.71 & 9.24 \\
\hline & London & 633 & Census tract & 2001 & $7,172,031$ & 10,070 & 11,330 & 12,760 & 6.26 & 7.80 & 9.68 \\
\hline & Zurich & 212 & Census tract & 2004 & 364,977 & 959 & 1618 & 2288 & 4.49 & 6.16 & 7.52 \\
\hline \multirow[t]{4}{*}{ Southern } & Turin & 2666 & Census tract & 2004 & 892,157 & 184 & 274 & 413 & 5.02 & 6.58 & 7.84 \\
\hline & Lisbon & 207 & Parish & 2001 & $2,661,850$ & 4123 & 9738 & 17,620 & 4.89 & 5.76 & 6.41 \\
\hline & Barcelona & 1491 & Census tract & 2004 & $1,588,404$ & 788 & 974 & 1225 & 5.61 & 6.99 & 8.75 \\
\hline & Madrid & 2358 & Census tract & 2005 & $3,149,615$ & 996 & 1239 & 1524 & 5.56 & 7.83 & 9.75 \\
\hline
\end{tabular}

*The population for one year within the study period is provided for descriptive purposes only.

$\mathrm{P}_{25}=25$ th percentile

$\mathrm{P}_{50}=50$ th percentile (median)

$\mathrm{P}_{75}=75$ th percentile 
Table 2: Number of deaths (n) and indirectly age-standardized mortality rate (ISMR) per 100,000 inhabitants, stratified by cause of death and sex.

\begin{tabular}{|c|c|c|c|c|c|c|c|c|c|c|c|c|c|c|c|c|c|c|}
\hline \multirow[t]{2}{*}{$\begin{array}{l}\text { European } \\
\text { Region }\end{array}$} & \multirow[t]{2}{*}{ City } & \multirow[t]{2}{*}{ Period } & \multicolumn{2}{|c|}{$\begin{array}{l}\text { Ischemic } \\
\text { heart } \\
\text { diseases }\end{array}$} & \multicolumn{2}{|c|}{$\begin{array}{l}\text { Cerebrovascul } \\
\text { ar } \\
\text { diseases }\end{array}$} & \multicolumn{2}{|c|}{$\begin{array}{l}\text { Lung } \\
\text { cancer }\end{array}$} & \multicolumn{2}{|c|}{$\begin{array}{l}\text { Prostatic } \\
\text { cancer } \\
\text { / Breast } \\
\text { cancer } \\
\end{array}$} & \multicolumn{2}{|c|}{$\begin{array}{l}\text { Respirator } \\
\text { y } \\
\text { diseases } \\
\end{array}$} & \multicolumn{2}{|c|}{$\begin{array}{l}\text { Influenza } \\
\text { and } \\
\text { Pneumonia }\end{array}$} & \multicolumn{2}{|c|}{$\begin{array}{l}\text { Chronic } \\
\text { liver } \\
\text { diseases }\end{array}$} & \multicolumn{2}{|c|}{ Diabetes } \\
\hline & & & $\mathbf{n}$ & ISMR & $\mathbf{n}$ & ISMR & $\mathbf{n}$ & ISMR & $\mathbf{n}$ & ISMR & $\mathbf{n}$ & $\begin{array}{l}\text { ISM } \\
\mathbf{R}\end{array}$ & $\mathbf{n}$ & $\begin{array}{l}\text { ISM } \\
\text { R }\end{array}$ & $\mathbf{n}$ & ISMR & $\mathbf{n}$ & $\begin{array}{l}\text { ISM } \\
\text { R }\end{array}$ \\
\hline \multicolumn{19}{|l|}{ Men } \\
\hline Northern & Helsinki & $\begin{array}{l}2000- \\
2009\end{array}$ & 4931 & $\begin{array}{l}303.8 \\
2\end{array}$ & 1512 & 97.56 & 1363 & 69.43 & 691 & 43.79 & 735 & & 640 & $\begin{array}{l}42.4 \\
9\end{array}$ & 950 & 42.77 & 240 & $\begin{array}{l}14.8 \\
6\end{array}$ \\
\hline Central- & $\begin{array}{l}\text { Stockhol } \\
\mathrm{m}\end{array}$ & $\begin{array}{l}2000- \\
2007 \\
2003-\end{array}$ & $\begin{array}{l}1177 \\
2\end{array}$ & $\begin{array}{l}205.9 \\
9 \\
285.3\end{array}$ & 4499 & 79.80 & 2773 & 45.76 & 3204 & 57.71 & 1816 & $\begin{array}{l}32.4 \\
3 \\
36.4\end{array}$ & 1572 & $\begin{array}{l}27.4 \\
2 \\
43.8\end{array}$ & 761 & 11.57 & $\begin{array}{l}107 \\
5\end{array}$ & $\begin{array}{l}18.9 \\
5 \\
11.8\end{array}$ \\
\hline \multirow[t]{4}{*}{ Eastern } & Prague & $\begin{array}{l}2007 \\
2000-\end{array}$ & 6113 & $\begin{array}{l}6 \\
437.5\end{array}$ & 2804 & 136.70 & 2368 & 91.69 & 967 & 45.00 & 777 & $\begin{array}{l}6 \\
21.2\end{array}$ & 839 & $\begin{array}{l}7 \\
62.0\end{array}$ & 659 & 23.81 & 254 & $\begin{array}{l}5 \\
18.0\end{array}$ \\
\hline & Bratislava & $\begin{array}{l}2008 \\
2000-\end{array}$ & 4833 & $\begin{array}{l}3 \\
530.6\end{array}$ & 876 & 83.56 & 1117 & 81.27 & 439 & 40.76 & 229 & $\begin{array}{l}3 \\
32.0\end{array}$ & 616 & $\begin{array}{l}3 \\
88.0\end{array}$ & 665 & 41.86 & 198 & $\begin{array}{l}1 \\
32.8\end{array}$ \\
\hline & Kosice & $\begin{array}{l}2008 \\
2001-\end{array}$ & $\begin{array}{l}2568 \\
2068\end{array}$ & $\begin{array}{l}8 \\
397.3\end{array}$ & 603 & 134.72 & 593 & $\begin{array}{l}90.64 \\
133.1\end{array}$ & 173 & 37.35 & 149 & $\begin{array}{l}6 \\
49.7\end{array}$ & 374 & $\begin{array}{l}1 \\
10.3\end{array}$ & 343 & 43.42 & $\begin{array}{l}158 \\
152\end{array}$ & $\begin{array}{l}7 \\
29.2\end{array}$ \\
\hline & Budapest & $\begin{array}{l}2008 \\
2001-\end{array}$ & 7 & $\begin{array}{l}7 \\
126.7\end{array}$ & 7778 & 153.18 & 7756 & 4 & 1911 & 36.76 & 2580 & $\begin{array}{l}9 \\
57.0\end{array}$ & 507 & $\begin{array}{l}1 \\
44.3\end{array}$ & 4371 & 71.98 & 2 & $\begin{array}{l}3 \\
12.5\end{array}$ \\
\hline \multirow[t]{5}{*}{ Western } & $\begin{array}{l}\text { Brussels } \\
\text { Amsterda }\end{array}$ & $\begin{array}{l}2004 \\
1996-\end{array}$ & 1784 & $\begin{array}{l}7 \\
173.4\end{array}$ & 866 & 62.32 & 1131 & $\begin{array}{l}75.61 \\
111.6\end{array}$ & 399 & 28.44 & 800 & $\begin{array}{l}6 \\
78.1\end{array}$ & 612 & $\begin{array}{l}0 \\
58.0\end{array}$ & 250 & 15.83 & $\begin{array}{l}177 \\
102\end{array}$ & $\begin{array}{l}6 \\
37.7\end{array}$ \\
\hline & $\begin{array}{l}\text { m } \\
\text { Rotterda }\end{array}$ & $\begin{array}{l}2008 \\
1996-\end{array}$ & 4733 & $\begin{array}{l}0 \\
180.8\end{array}$ & 2498 & 94.42 & 3491 & $\begin{array}{l}1 \\
122.1\end{array}$ & 1336 & 50.75 & 2075 & $\begin{array}{l}3 \\
85.4\end{array}$ & 1533 & $\begin{array}{l}4 \\
60.9\end{array}$ & 445 & 12.04 & 6 & $\begin{array}{l}6 \\
34.2\end{array}$ \\
\hline & $\mathrm{m}$ & $\begin{array}{l}2008 \\
2000-\end{array}$ & $\begin{array}{l}4836 \\
4690\end{array}$ & $\begin{array}{l}0 \\
234.3\end{array}$ & 2471 & 94.20 & $\begin{array}{l}3570 \\
1724\end{array}$ & 2 & 1343 & 50.81 & $\begin{array}{l}2262 \\
1319\end{array}$ & $\begin{array}{l}5 \\
66.7\end{array}$ & $\begin{array}{l}1588 \\
1516\end{array}$ & $\begin{array}{l}5 \\
76.9\end{array}$ & 326 & 10.30 & $\begin{array}{l}917 \\
283\end{array}$ & $\begin{array}{l}9 \\
14.1\end{array}$ \\
\hline & London & $\begin{array}{l}2008 \\
2000-\end{array}$ & 3 & $\begin{array}{l}9 \\
171.3\end{array}$ & 17654 & 89.92 & 2 & 78.99 & 8007 & 40.63 & 9 & $\begin{array}{l}9 \\
30.8\end{array}$ & 7 & $\begin{array}{l}4 \\
17.0\end{array}$ & 4339 & 18.19 & 3 & $\begin{array}{l}6 \\
22.1\end{array}$ \\
\hline & Zurich & $\begin{array}{l}2008 \\
2000-\end{array}$ & 2374 & $\begin{array}{l}9 \\
122.7\end{array}$ & 841 & 60.40 & 880 & $\begin{array}{l}65.14 \\
101.1\end{array}$ & 579 & 42.67 & 423 & $\begin{array}{l}9 \\
42.0\end{array}$ & 243 & $\begin{array}{l}3 \\
29.4\end{array}$ & 192 & 13.43 & 306 & $\begin{array}{l}7 \\
20.0\end{array}$ \\
\hline \multirow[t]{4}{*}{ Southern } & Turin & $\begin{array}{l}2008 \\
1995-\end{array}$ & $\begin{array}{l}4961 \\
2355\end{array}$ & $\begin{array}{l}3 \\
189.2\end{array}$ & 3892 & 98.23 & $\begin{array}{l}4465 \\
1116\end{array}$ & 8 & 1129 & 27.36 & 1716 & $\begin{array}{l}7 \\
43.3\end{array}$ & 1114 & $\begin{array}{l}4 \\
59.1\end{array}$ & 872 & 20.08 & $\begin{array}{l}816 \\
552\end{array}$ & $\begin{array}{l}6 \\
44.2\end{array}$ \\
\hline & $\begin{array}{l}\text { Lisbon } \\
\text { Barcelon }\end{array}$ & $\begin{array}{l}2008 \\
2000-\end{array}$ & 2 & $\begin{array}{l}6 \\
110.5\end{array}$ & 23437 & 198.40 & 9 & $\begin{array}{l}72.58 \\
101.0\end{array}$ & 5643 & 45.38 & 5345 & $\begin{array}{l}7 \\
60.7\end{array}$ & 6585 & $\begin{array}{l}0 \\
17.5\end{array}$ & 4149 & 25.04 & $\begin{array}{l}5 \\
159\end{array}$ & $\begin{array}{l}9 \\
23.6\end{array}$ \\
\hline & $a$ & $\begin{array}{l}2008 \\
2000-\end{array}$ & $\begin{array}{l}7412 \\
1122\end{array}$ & $\begin{array}{l}5 \\
115.9\end{array}$ & 4705 & 70.53 & $\begin{array}{l}6953 \\
1040\end{array}$ & 1 & 1803 & 26.54 & 4100 & $\begin{array}{l}0 \\
53.6\end{array}$ & 1144 & $\begin{array}{l}1 \\
44.3\end{array}$ & 1215 & 17.89 & $\begin{array}{l}0 \\
128\end{array}$ & $\begin{array}{l}0 \\
13.1\end{array}$ \\
\hline & Madrid & 2007 & 8 & 6 & 5970 & 62.85 & 3 & 98.38 & 2995 & 30.34 & 5242 & 7 & 4038 & 9 & 1442 & 13.51 & 0 & 2 \\
\hline
\end{tabular}




\section{Women}

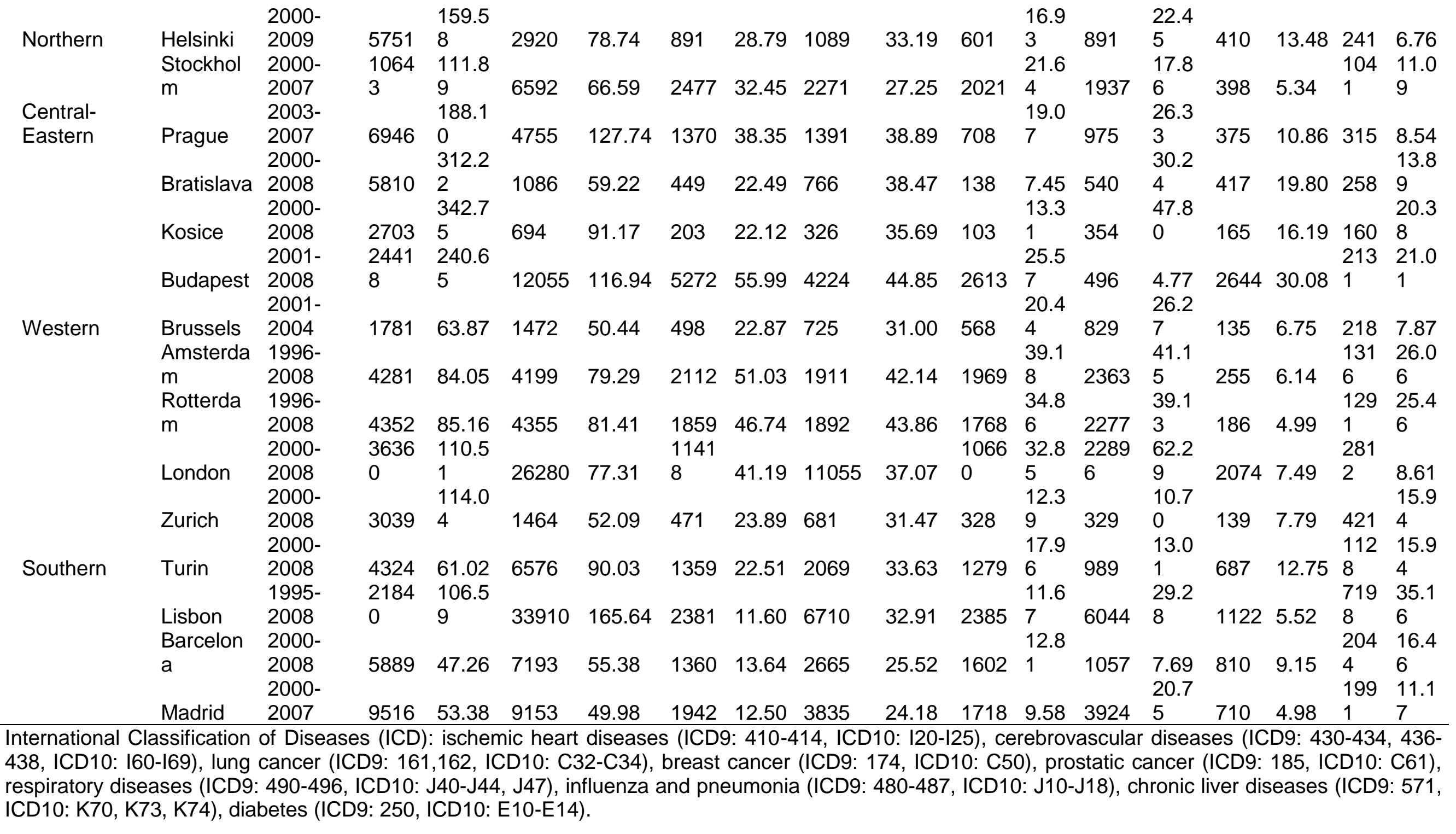




\section{References}

1 United Nations Population Division D of E and SA. World Urbanization Prospects, the 2011 Revision: Highlights. 2012.

$2 \quad$ Borrell C, Pons-Vigués M, Morrison J, et al. Factors and processes influencing health inequalities in urban areas. J Epidemiol Community Health 2013;67:38991. doi:10.1136/jech-2012-202014; 10.1136/jech-2012-202014

3 Kunst AE, Groenhof F, Andersen O, et al. Occupational class and ischemic heart disease mortality in the United States and 11 European countries. Am J Public Health 1999;89:47-53.

$4 \quad$ Mackenbach JP, Cavelaars AE, Kunst AE, et al. Socioeconomic inequalities in cardiovascular disease mortality; an international study. Eur Heart $J$ 2000;21:1141-51. doi:10.1053/euhj.1999.1990

5 Van der Heyden JH a, Schaap MM, Kunst a E, et al. Socioeconomic inequalities in lung cancer mortality in 16 European populations. Lung Cancer 2009;63:32230. doi:10.1016/j.lungcan.2008.06.006; 10.1016/j.lungcan.2008.06.006

6 Huisman M, Kunst AE, Bopp M, et al. Educational inequalities in cause-specific mortality in middle-aged and older men and women in eight western European populations. Lancet 2005;365:493-500. doi:10.1016/S0140-6736(05)17867-2

7 Avendano $M$, Kunst AE, Huisman M, et al. Socioeconomic status and ischaemic heart disease mortality in 10 western European populations during the 1990s. Heart 2006;92:461-7. doi:10.1136/hrt.2005.065532

8 Mackenbach JP, Stirbu I, Roskam AJ, et al. Socioeconomic inequalities in health in 22 European countries. N Engl J Med 2008;358:2468-81.

doi:10.1056/NEJMsa0707519

9 Menvielle G, Kunst AE, Stirbu I, et al. Educational differences in cancer mortality among women and men: a gender pattern that differs across Europe. $\mathrm{Br} \mathrm{J}$ Cancer 2008;98:1012-9. doi:10.1038/sj.bjc.6604274; 10.1038/sj.bjc.6604274

10 Mackenbach JP, Huisman M, Andersen O, et al. Inequalities in lung cancer mortality by the educational level in 10 European populations. Eur $\mathrm{J}$ Cancer 2004;40:126-35.

11 Corburn J, Cohen AK. Why we need urban health equity indicators: integrating science, policy, and community. PLoS Med 2012;9:e1001285. doi:10.1371/journal.pmed.1001285; 10.1371/journal.pmed.1001285

12 Borrell C, Marí-Dell'olmo M, Serral G, et al. Inequalities in mortality in small areas of eleven Spanish cities (the multicenter MEDEA project). Health Place 2010;16:703-11. doi:10.1016/j.healthplace.2010.03.002

13 Gotsens M, Mari-Dell'Olmo M, Martinez-Beneito MA, et al. Socio-economic inequalities in mortality due to injuries in small areas of ten cities in Spain (MEDEA Project). Accid Anal Prev 2011;43:1802-10.

doi:10.1016/j.aap.2011.04.013; 10.1016/j.aap.2011.04.013 
14 The INEQ-CITIES project: Socioeconomic inequalities in mortality in cities of Europe. ;2013.https://www.ucl.ac.uk/ineqcities/

15 Borrell C, Marí-Dell'olmo M, Palència L, et al. Socioeconomic inequalities in mortality in 16 European cities. Scand J Public Health 2014;42:245-54. doi:10.1177/1403494814522556

16 The INEQ-CITIES Atlas. ;2013.https://www.ucl.ac.uk/ineqcities/atlas

17 Salcedo N, Saez M, Bragulat B, et al. Does the effect of gender modify the relationship between deprivation and mortality? BMC Public Health 2012;12:574. doi:10.1186/1471-2458-12-574

18 Hoffmann R, Borsboom G, Saez M, et al. Social differences in avoidable mortality between small areas of 15 European cities: an ecological study. Int $J$ Health Geogr 2014;13:8. doi:10.1186/1476-072X-13-8

19 Copenhagen WRO for E. European Detailed Mortality Database (DMDB). ;2011.http://data.euro.who.int/dmdb/

20 Besag J, York J, Mollié A. Bayesian image restoration, with two applications in spatial statistics. Ann Inst Stat Math 1991;43:1-59. doi:10.1007/BF00116466

21 Team. RDC. R: A Language and Environment for Statistical Computing. 2013.http://www.r-project.org/

22 Gelman A. Prior distributions for variance parameters in hierarchical models. Bayesian Anal 2006;1:515-33.

23 Rue H, Martino S. INLA: Functions which allow to perform a full Bayesian analysis of structured additive models using Integrated Nested Laplace Approximaxion. R package version 0.0. 2009.

24 Rue H, Martino S, Chopin N. Approximate Bayesian inference for latent Gaussian models by using integrated nested Laplace approximations. J R Stat Soc Ser B (Statistical Methodol 2009;71:319-92.

25 Espelt A, Borrell C, Roskam AJ, et al. Socioeconomic inequalities in diabetes mellitus across Europe at the beginning of the 21st century. Diabetologia 2008;51:1971-9. doi:10.1007/s00125-008-1146-1; 10.1007/s00125-008-1146-1

26 Gallo V, Mackenbach JP, Ezzati M, et al. Social inequalities and mortality in Europe--results from a large multi-national cohort. PLoS One 2012;7:e39013. doi:10.1371/journal.pone.0039013; 10.1371/journal.pone.0039013

27 Marmot M, Allen J, Bell R, et al. WHO European review of social determinants of health and the health divide. Lancet 2012;380:1011-29. doi:10.1016/S01406736(12)61228-8; 10.1016/S0140-6736(12)61228-8

28 Benach J, Yasui Y, Borrell C, et al. Material deprivation and leading causes of death by gender: evidence from a nationwide small area study. J Epidemiol Community Health 2001;55:239-45. 
29 Rendall M, Couet C, Lappegard T, et al. First births by age and education in Britain, France and Norway. Popul Trends 2005;:27-34.

30 Rendall M, Aracil E, Bagavos C, et al. Increasingly heterogeneous ages at first birth by education in Southern European and Anglo-American family-policy regimes: A seven-country comparison by birth cohort. Popul Stud (NY) 2010;64:209-27. doi:10.1080/00324728.2010.512392

31 Puigpinos-Riera R, Mari-Dell'Olmo M, Gotsens M, et al. Cancer mortality inequalities in urban areas: a Bayesian small area analysis in Spanish cities. Int J Health Geogr 2011;10:6. doi:10.1186/1476-072X-10-6

32 Tjønneland A, Christensen J, Olsen A, et al. Alcohol intake and breast cancer risk: the European Prospective Investigation into Cancer and Nutrition (EPIC). Cancer Causes Control 2007;18:361-73. doi:10.1007/s10552-006-0112-9

33 Palència L, Espelt A, Rodríguez-Sanz M, et al. Socio-economic inequalities in breast and cervical cancer screening practices in Europe: influence of the type of screening program. Int J Epidemiol 2010;39:757-65. doi:10.1093/ije/dyq003

34 Merletti F, Galassi C, Spadea T. The socioeconomic determinants of cancer. Environ Health 2011;10 Suppl 1:S7. doi:10.1186/1476-069X-10-S1-S7

35 Santana P. Poverty, social exclusion and health in Portugal. Soc Sci Med 2002;55:33-45.

36 Mackenbach JP, Kunst AE, Cavelaars AE, et al. Socioeconomic inequalities in morbidity and mortality in western Europe. The EU Working Group on Socioeconomic Inequalities in Health. Lancet 1997;349:1655-9.

37 Mackenbach JP. The persistence of health inequalities in modern welfare states: the explanation of a paradox. Soc Sci Med 2012;75:761-9.

doi:10.1016/j.socscimed.2012.02.031; 10.1016/j.socscimed.2012.02.031

38 Jackson $\mathrm{AL}$, Davies $\mathrm{C}$ a, Leyland $\mathrm{AH}$. Do differences in the administrative structure of populations confound comparisons of geographic health inequalities? BMC Med Res Methodol 2010;10:74. doi:10.1186/1471-2288-1074

39 Openshaw S. Optimal zoning systems for spatial interaction models. Environ Plan A 1977;9:169-84.

40 Halonen JI, Vahtera J, Oksanen T, et al. Socioeconomic characteristics of residential areas and risk of death: is variation in spatial units for analysis a source of heterogeneity in observed associations? BMJ Open 2013;3:10.1136/bmjopen-2012-002474. Print 2013. doi:10.1136/bmjopen-2012002474; 10.1136/bmjopen-2012-002474

41 Meliker JR, Goovaerts P, Jacquez GM, et al. Breast and prostate cancer survival in Michigan: can geographic analyses assist in understanding racial disparities? . Cancer 2009;115:2212-21. doi:10.1002/cncr.24251; 10.1002/cncr.24251 
42 Copeland $\mathrm{G}$. The role of public health and how boundary analysis can provide a tool for public health investigations: The public health perspective. Spat Spatiotemporal Epidemiol 2010;1:201-5.

43 Ompad DC, Galea S, Caiaffa WT, et al. Social determinants of the health of urban populations: methodologic considerations. J Urban Health 2007;84:i4253. doi:10.1007/s11524-007-9168-4

44 Camprubi L, Diez E, Morrison J, et al. The Ineq-Cities research project on urban health inequalities: knowledge dissemination and transfer in Spain. Gac Sanit 2013;28:166-9. doi:10.1016/j.gaceta.2013.05.005;

10.1016/j.gaceta.2013.05.005 